\title{
Design Thinking In Pharmacy Education: Inspiring Creative Problem Solving in the Next Generation of Pharmacists
}

Robert S. Pugliese, PharmD, BCPS, Gianna Girone, PharmD Candidate 2018

Thomas Jefferson University, Jefferson College of Pharmacy

\begin{abstract}
Born from the world of product and service innovation, design thinking is gaining popularity as a method for introducing creative problem solving into the education of health professionals. Mindsets developed through practicing design thinking can help learners and educators address complex healthcare issues in a whole new way. This article aims to introduce the concepts of design thinking to the pharmacy educator, give examples of its use in pharmacy education, and discuss the value of including it in pharmacy education from both an educator and a student's perspective.
\end{abstract}

\section{PREFACE}

In this two part commentary, we introduce readers to the concept of design thinking from the perspective of a pharmacy educator and a pharmacy student and discuss ways this process can be used to drive innovation in pharmacy. In the first part, you will hear from Robert Pugliese, a pharmacy educator and clinician who has spent the last 3 years exploring the intersection of design and healthcare. In part two, you will hear from a current pharmacy student, Gianna Girone, who was exposed to design thinking in pharmacy school and who hopes that more students will have the opportunity to learn this methodology.

\section{PART 1: by Robert Pugliese, PharmD, BCPS} Introduction

Within some health profession schools, design thinking is gaining popularity as a method for introducing creative problem solving into the curriculum with hopes of better preparing graduates for the complex world of healthcare. The larger healthcare industry has already embraced design thinking as it has been integral to the development of many healthcare adjacent products and services. Some highly publicized examples of design thinking within the pharmacy industry include the innovative PillPack pharmacy, Walgreens Well Experience, and CVS ScriptPath Prescription Schedule System, all of which were developed with some element of design thinking principle. While professional designers have practiced de facto design thinking for decades to make beautiful and functional products, those on the front lines of healthcare are now beginning to realize that thinking like both a healthcare provider and a designer can help us to better understand and solve some of the wicked problems endemic to the healthcare system. In response to this need for new tools to help address some of these problems, healthcare providers and educators have begun to learn, teach, and utilize design thinking to jumpstart innovation and solve real problems.

Corresponding Author: Robert S. Pugliese, PharmD, BCPS Emergency Medicine Clinical Pharmacist, Dept. of Pharmacy Clinical Assistant Professor, College of Pharmacy Associate Dir, JeffDESIGN, The Sidney Kimmel Medical College Founding Director, Health Design Lab @JeffInnovation Thomas Jefferson University and Hospital 111 South 11th St, Suite 2260, Philadelphia, PA 19107 Email: robert.pugliese@jefferson.edu

\section{Science versus Design}

Design thinking, a term popularized by the international design firm IDEO and the Hasso Plattner Institute of Design (d.school) at Stanford University, grew from the epistemological study of design and how it differs from traditional science methodology. ${ }^{1}$ This differentiation is best described by the quote,

\begin{abstract}
"The scientific method is a pattern of problemsolving behavior employed in finding out the nature of what exists, whereas the design method is a pattern of behavior employed in inventing things...which do not yet exist. Science is analytic; design is constructive". ${ }^{2}$
\end{abstract}

Understanding this difference helps us to understand how healthcare, a traditionally scientific endeavor, can benefit from the methods used by designers to create novel solutions within complex and dynamic systems. This is not to say that designers do not apply robust scientific methods to understand the system in which they are designing, but the goals of design are to create new structures, whereas science is to understand existing structures. Notable is that the term "wicked problem", a term that has been adopted to explain many of the issues we face in healthcare today, was first described by a designer in $1973 .{ }^{3}$ The term defines a problem or design challenge that is so complex and variable that it is impossible to pin down with a simple "solution." Today's healthcare system is rife with so-called wicked problems, so it seems fitting that design methods would be used in an attempt to address them. 


\section{What is Design Thinking?}

Design thinking is frequently defined in one of two ways. Designers at IDEO first described it as a method for innovation that occurs at the confluence of desirability, feasibility, and viability (Figure 1). Educators at The d.school described a series of five steps in a design thinking cycle beginning with empathy and ending with testing (Figure 2). Both of these descriptions are similar in that the goal is the creation of something "innovative" and that the process is iterative with repeating cycles of construction and reflection. This repeating nature assures that cycles that end in "failure" are opportunities for learning and refinement of the concept in the next iteration or version. While the most talked about designs frequently incorporate technology into the solution, some of the best solutions are simple ones. Using one example from a class, we challenged students to address medication reconciliation in the emergency department using design thinking. Students initially wanted to develop an app in an attempt to solve the challenge, however the design process led them somewhere they didn't expect. Students spent the semester interviewing patients and providers, developing a deep understanding for the barriers involved, developed numerous data collection forms, and tested many process iterations before settling on a simple paper form to guide history taking. An app may have taken years to develop and implement, but a paper form fit into the department workflow and was developed in just a couple weeks.

Ultimately, the goal of the design thinking educator is to have learners experience the design thinking process many times over and develop mindsets that bring them closer to achieving "creative confidence" or a capacity to effect change in themselves and their environment, in order to support successful problem-solving. ${ }^{4}$ To become comfortable with the design process, specific mindsets, such as "bias towards action, radical collaboration, human centeredness, constant reframing, and iteration," (Table 1) are practiced to help learners realize creative potential and, in combination with other diverse latent talents, lead to creative confidence. ${ }^{5}$ It is important to understand that the design thinking process is rarely linear, and as learners become comfortable with these mindsets, there is no specific order or "right way" as a concept progresses. In fact, one of the earliest lessons those in healthcare must learn, when practicing design thinking, is how to be comfortable with ambiguity, as true creativity is often found outside of traditional boundaries.

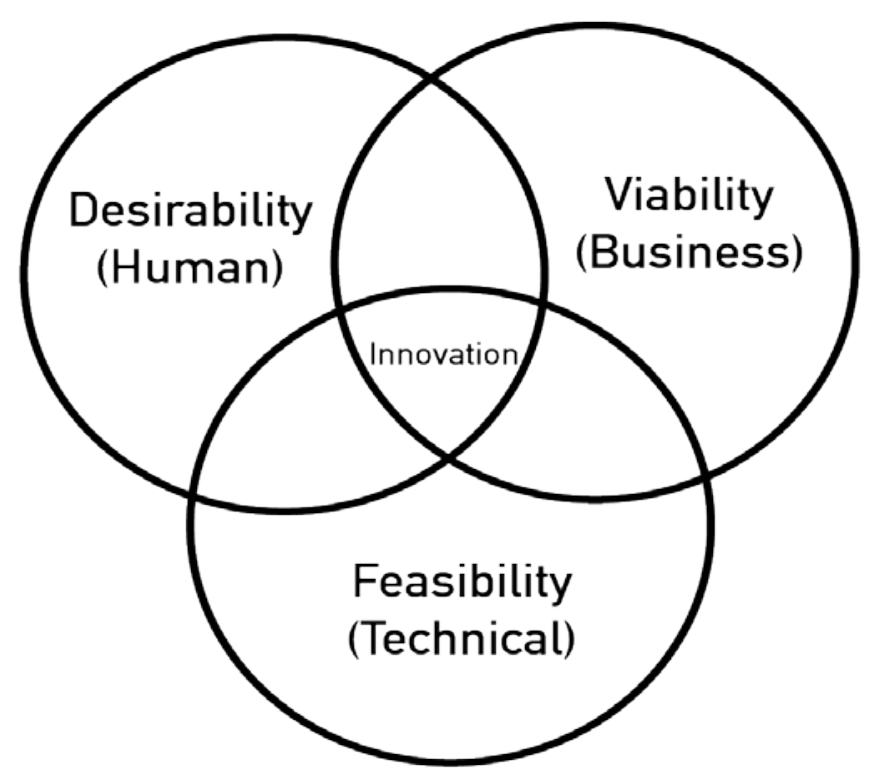

Figure 1: Design thinking model as developed by IDEO 


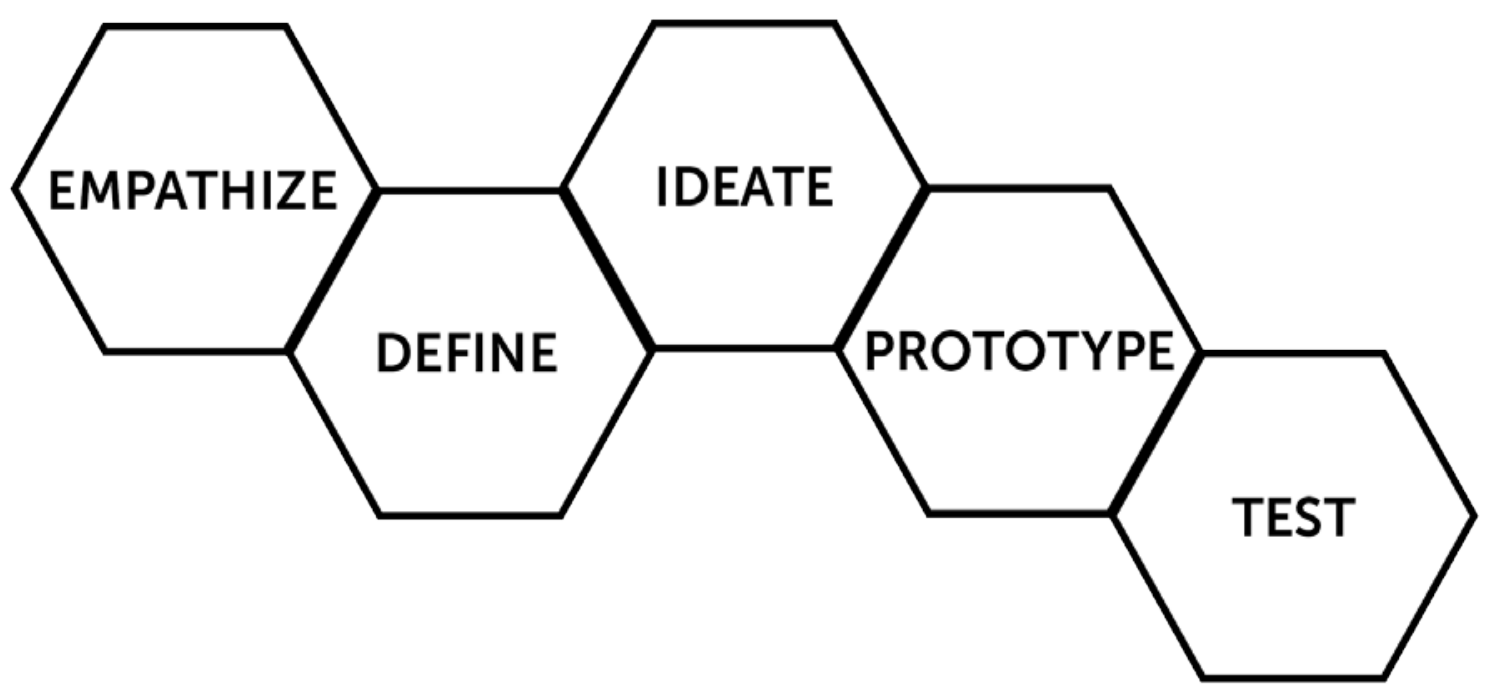

Figure 2: Design thinking model as developed within the Hasso Plattner Institute of Design (d.school) at Stanford University

Table 1. Examples of Design Thinking Mindsets ${ }^{4,5}$

\begin{tabular}{|c|c|c|}
\hline Human Centeredness & $\begin{array}{l}\text { People are the source of inspiration and } \\
\text { direction for solving design challenges }\end{array}$ & $\begin{array}{l}\text { - Users = people you are designing for } \\
\text { - } \quad \text { Every design cycle starts and ends with gaining } \\
\text { empathy } \\
\text { - } \quad \text { Don't make assumptions } \\
\text { - } \quad \text { Listen, observe, and experience your users' reality }\end{array}$ \\
\hline Radical Collaboration & $\begin{array}{l}\text { Radically diverse multidisciplinary teams } \\
\text { will lead to greater } \\
\text { innovation }\end{array}$ & $\begin{array}{l}\text { - All interest groups should be represented in your } \\
\text { process } \\
\text { - } \quad \text { Design solutions WITH your users } \\
\text { - Get far away from traditional silos }\end{array}$ \\
\hline Bias Towards Action & $\begin{array}{l}\text { Focus on action-oriented behavior } \\
\text { rather than discussion-based work }\end{array}$ & $\begin{array}{l}\text { - Don't be afraid to show and test your work before } \\
\text { it's perfect } \\
\text { - } \quad \text { Break a solution down to testable variables } \\
\text { - } \quad \text { Rapidly prototype your idea in low resolution and } \\
\text { test it quickly } \\
\text { - } \quad \text { Fail fast and learn quickly }\end{array}$ \\
\hline Constant Reframing & $\begin{array}{l}\text { Take nothing at face value and look for } \\
\text { root-causes of problems }\end{array}$ & $\begin{array}{l}\text { - Any problem is a potential design challenge } \\
\text { - Look at problems from the point of view of your } \\
\text { users } \\
\text { - Ask five whys to find the problems behind the } \\
\text { problems } \\
\text { - One impossible idea can inspire ten great realistic } \\
\text { ones }\end{array}$ \\
\hline Iteration & Designs are refined with iterative cycles & $\begin{array}{l}\text { - The goal of each design cycle is incremental } \\
\text { improvement and not perfection } \\
\text { - } \quad \text { Empathize, define, ideate, prototype, test, repeat. } \\
\text { - } \quad \text { Failure is essential for improvement } \\
\text { - There is no right way, but diligence is essential }\end{array}$ \\
\hline
\end{tabular}




\section{Design Thinking in Pharmacy Education}

While design thinking was born from the need to create new ideas and concepts, in the hands of educators, it can be a powerful tool for creating innovators. Pharmacy educators and students have begun to use design thinking concepts to fill a need for innovation and new ways of thought within the profession. In programs, such as the Pharmacy Innovation Lab at University of Pittsburgh, students experience design thinking and entrepreneurship by learning how patients interact with technology and develop new pharmacy related technologies. ${ }^{6}$ Another example of students seeking out design focused learning experiences is The Emerging Leaders Program, at Stanford Medicine X, where pharmacy and other health profession students participate in a semester long co-creative experience as they are paired up with patients to share perspectives and practice empathy building, a key mindset of design thinking. ${ }^{7}$ Our Medicine+Design program and Health Design Lab at Thomas Jefferson University, the vision of Dean and Provost Dr. Mark Tykocinski, were created with the goals of breaking down traditional silos in health care and training the next generation of clinicians to be creative problem solvers. ${ }^{8} \mathrm{An}$ example of a Medicine+Design multidisciplinary course was one where students worked directly alongside individuals afflicted with disabilities to develop custom accessibility solutions. ${ }^{9}$ In this course, design thinking becomes the common language that allows medical, industrial design, occupational therapy, and pharmacy students to communicate and work towards a common goal. The most essential ingredient of this collaboration, however, is the involvement of the patient. While the primary goal is to create a new and innovative solutions to help the patient in the group, the educational goals span from practicing user centered approaches, to rapidly prototyping concepts, using tools ranging from craft supplies to $3 \mathrm{D}$ printers. In each of these unique examples, students are challenged to think creatively by being exposed to new perspectives and skills outside the normal realm of pharmacy education. And while they may not at face value appear to address key pharmacy education goals, what students learn during these experiences directly address a number of educational standards.

The 2016 American Council for Pharmacy Education Standards (ACPE 2016) list innovation and entrepreneurship as an educational goal and specifically states that students should engage in "creative thinking to envision better ways of accomplishing professional goals" ${ }^{10}$ Simply learning how to apply the basic steps of the design thinking process help students address this requirement. The Center for the Advancement of Pharmacy Education (CAPE 2013) educational outcomes are split into 4 domains and numerous subdomains, many of which address knowledge and skills that could be learned with design thinking methods. ${ }^{11}$ While the "ProblemSolving" subdomain is the most obvious area where a design thinking methodology could be applied to help students become more proficient problem solvers, design thinking mindsets could be beneficial when applied to many others. For example, in the "Caregiver" subdomain, communication techniques used to gain empathy could help students be better caregivers. Under the "Manager" subdomain, design thinking methods helpful for solving wicked problems would certainly benefit students who are learning to manage complex systems. The co-creative and radically collaborative approach to problem solving in design thinking would be relevant to many domains including the "Advocate", "Collaborator", "Includer", and "Communicator" subdomains. And the focus on developing creative agency and metacognition in design thinking can help guide students in the "Self-aware", "Leader", and "Innovator" subdomains. As one begins to understand the skills and mindsets of design thinking, the benefits of applying them across the pharmacy education spectrum become apparent.

The Introductory Pharmacy Practice Experiences (IPPEs) and Advanced Pharmacy Practice Experiences (APPEs) are another focus for innovation in the ACPE 2016 standards. ${ }^{10}$ Many colleges have developed advanced experiences for students in areas, such as health informatics and marketing, which allow them to practice unique forms of patient care and work with diverse teams that more closely resemble the working world. The application of design thinking mindsets, such as humancenteredness and radical collaboration, in experiential rotations can help to reimagine the possibilities within these experiences. For example, if human centeredness continues to be a core skill of the modern healthcare provider, then an experience in which students shadow a journalist and learn the skills which allow one to empathize better with others would be invaluable. As another example, many healthcare professionals find themselves in operational and administrative roles after graduation. An internship at Amazon or a Silicon Valley startup may better prepare them to be innovative pharmacy leaders. As patient educators, most of the pharmacist's role relies on skills in communication, and therefore an improvisation workshop or graphic design course may be just as impactful as a patient counseling course. The argument here is not that we need to replace our core teaching, but that we can address these core skills and improve upon them by opening our professional horizon and learning from what other professions do best.

Lastly, and potentially the most critical to the future of the pharmacy profession, is the use of design thinking to foster innovation in teaching and learning. Programs, such as The University Innovation Fellows and Teaching Learning Studio at the Stanford d.school, train both college students and educators to be change-makers at their home institutions by empowering them with the tools of design thinking. Student fellows of the program have done everything from starting a makerspace at their university ${ }^{12}$ to developing new and 
innovative courses along with professors ${ }^{13}$. As an educator who participated in this program, I spent a week immersed in the unique learning environment of the Stanford d.school and left having experienced a unique form of pedagogy and armed with new tools to completely rethink how to approach teaching. One of the essential design thinking lessons taught to educators is the concept of co-creation. Co-creation is the bringing together of different parties (i.e. teacher and learner or educators from different disciplines) to create something of mutual value. As an example, each course at the d.school is co-taught by at least two educators with different backgrounds. Courses are also usually put through a test phase where learners can experience a highly condensed version of the course and provide immediate feedback as the course is developed further. While not inherently innovative, co-creation is incredibly powerful when applied to things that are traditionally decided unilaterally, such as college level courses, patient care plans, and other areas where there is a knowledge, skill, or power differential. While many educators include their students in the development of courses by eliciting feedback at the end, a design thinking approach starts with building empathy, the first and arguably most important design thinking mindset. Gaining empathy requires a deep study and understanding of the individuals for which a concept is being designed by using tools such as observation, engagement, immersion, and research. A designer will often face any challenge by first conducting "needfinding" with users, being sure that their needs are well understood and avoiding assumptions. Pharmacy educators interested in creating innovative educational experiences should be sure to not just understand students, but to also create experiences in collaboration with them.

\section{How to Get Started}

If you are an educator who would like to begin to use or teach design thinking, how do you get started? As explained earlier, the design thinking process is best learned through experience and there are many resources to get started online. A Virtual Crash Course in Design Thinking, available free on the d.school website, is a 90-minute exercise best done in a group and is the perfect way to begin to learn the process. Educators can also attend live programing to experience design thinking with programs such as the Teaching Learning Studio and other events, boot camps, and hackathons that incorporate design thinking. If you are an educator looking to develop a unique experience, in the spirit of encouraging a multidisciplinary mindset, you should consider looking outside of the profession and collaborate with a design professional. Start by looking in your own institution for collaborators within a design, engineering or business school. Within health science universities, our occupational therapy colleagues are excellent practitioners of human centered design methods and great collaborators. Looking to health systems, many may have innovation centers or design groups who may be willing to collaborate on an educational activity. And lastly look for local design firms, who may have an interest in collaborating, as educational endeavors are mutually beneficial for their teams to gain exposure into new professional domains. We have used every single one of these methods to build our own creative confidence and create unique learning experiences at Jefferson that expose our health profession students to the world of design.

\section{PART 2: by Gianna Girone, PharmD Candidate 2018 A Student Perspective}

As a pharmacy student, just weeks from achieving my goal of becoming a pharmacist, I am incredibly optimistic and excited about the future of healthcare. Even more exciting, is that while healthcare has grown in its complexity, the field of pharmacy has expanded simultaneously. For me this evolution has inspired confidence about the future of pharmacy, especially knowing that pharmacists are stepping into fields that are at the forefront of innovation and discovery. Our training has also led us to pursue inclusion in non-traditional fields, such as marketing, telemedicine, and informatics, while further supporting our transition into the provider role. However, the same advancements that have created these new opportunities have also contributed to the notorious complexity surrounding healthcare, further complicating an already nebulous system. Pharmacists are frequently tasked with combating the confusion within the healthcare system because they are seen as the most accessible healthcare providers and valued as problem solvers by both patients and providers alike.
In my experiential work, I have observed my pharmacist preceptors presented with problems that are outside the realm of anything typically learned in pharmacy school. Issues like accessibility and affordability are so broad and pervasive that often times I find myself at a loss on how to help my patients navigate them. As a student, I am intensely focused on knowing the right answer to any problem encountered. However, my experience outside of the classroom has taught me that problems with just one answer do not exist in practice, and it can be difficult to reconcile this with everything I have learned in the classroom. A large part of our didactic pharmacy education is devoted to learning critical thinking skills so that we are prepared to address the myriad of complex problems associated with medication use. However as we begin experiential rotations, residency, and employment, we encounter a level of complexity that traditional didactics simply cannot prepare us for. If we devise ways to prepare pharmacy students to meet complex challenges by teaching creativethinking strategies alongside critical-thinking strategies, early in their didactic course work, they should be better prepared to address these challenges as pharmacists. This can be done by 
revamping curriculums, giving students an opportunity to practice addressing problems that do not have a single correct answer, and focusing on design thinking tenets such as cocreation and ideation as the core of our problem-solving skills. If we are to continue being looked upon as the problem solvers and navigators of our healthcare system, we will need to consider how equipped we are as a profession to confront the complexities associated with the shifting landscape. Strengthening pharmacy students as creative innovators through the incorporation of design thinking into pharmacy education may be a solution.

\section{Pharmacists as Problem Solvers}

If you trace back to the roots of pharmacy you'll find that pharmacists have always been design minded innovators, using our unique skills to find creative solutions to patient-care related problems. The first pharmacists compounded medicines from a variety of herbal and elemental substances to alleviate suffering and cure disease, while also making them pharmaceutically elegant, attractive, and palatable. Today's pharmacists continue to bring together disparate resources to find solutions to modern day problems and address issues, such as medication safety and access, in many different settings. Whether we realize it or not, these problems require creative thinking to solve, especially in situations where resources are limited and where we are troubled by the broader issues of access, literacy and affordability. During my ambulatory care APPE rotation, I discovered that I could address problems with health literacy by harnessing my creativity to reframe medical concepts in a more visual context. I had one patient who had trouble understanding the purpose of basal and bolus insulin regimens, so I sketched out the differences on how they both affect blood glucose. As a visual learner myself, I empathized with his struggle to grasp these medical concepts, and I used my creativity to communicate more effectively when traditional methods of communication were not working. I never imagined that utilizing my creativity to reframe problems would help me to better connect with my patients by adopting a visual language that met their needs. Only by empathizing with my patient's needs and reframing the challenge of health literacy did I realize the value of design thinking in problem solving.

\section{Pharmacists as Designers}

Many aspects of design thinking and creative problem solving are inherently built into the pharmacy curriculum. At Thomas Jefferson University College of Pharmacy some of our courses are centered around developing user-centered mindsets, an important skill in design thinking that emphasizes the ability to understand a user, commonly the "patient" or "caregiver", and their unique point of view. To those who haven't been introduced to design thinking, the presence of these concepts may not be immediately apparent during the experience, but it goes to show how some of the design thinking tenets are already present in our pharmacy curriculum. Courses such as
Interprofessional Grand Rounds employed a user-centered focus by allowing students to formulate the class content online in blog-style posts called "Wiki"s. Collaboration was a key focus of this class, as pharmacy students and students of other medical professions worked together to write posts about relevant course topics including "Big Pharma", vaccination requirements, and assisted reproduction. From my experience this user-focused course, that was essentially co-created live with students, spurred interesting discussions and enabled us to experience diverse perspectives. Another innovative class, Pharmacy Management, cultivated entrepreneurial and creative mindsets by challenging students to design and market their own pharmacy-related product as a final project. Innovative educational experiences such as this course gave us exposure to design thinking principles, albeit inadvertently. If we emphasized these design methods overtly in classes such as this, it would allow pharmacy students to actively reflect on the benefits of co-creation and user-centeredness in problem solving and assure these important learning objectives are being addressed.

Our IPPEs and APPEs were another part of the curriculum that fostered co-creation and radical collaboration, two core concepts in design thinking. For example, one of my first IPPEs was at a multidisciplinary clinic where medical, pharmacy, sociology and psychiatric professionals collaborated to improve patient access to HIV/AIDS care in Philadelphia. APPE rotations also provoked the understanding of new perspectives by offering experiences in non-traditional pharmacy roles such as automation, informatics, and marketing. It was only after learning design thinking during my experience at the Jefferson Health Design Lab that I was able to understand and gain a new appreciation for the power of these creative concepts and their potential for application across a range of practice sites. Reflecting back on my four years in pharmacy school, it is easy to pick out multiple courses that incorporate elements of design thinking, and I consider them all an invaluable to my overall pharmacy education. Going forward, I believe these concepts should be highlighted so that pharmacy students begin to build creative confidence and characterize themselves as design thinkers.

\section{Designing the Future}

How do we further incorporate design thinking into the pharmacy curriculum so that we continue to graduate innovators who are able to thrive in today's rapidly changing healthcare landscape? I believe that opening our space to the voices of others beyond pharmacy is the first step. For example, inviting engineers, designers, and artists into a pharmacy course could help us to bring new perspectives to devise innovative methods of improving adherence. If we look to the gaming industry, utilizing methods of gamification can benefit students by stimulating latent motivation to learn. Gamification can include virtual reality simulation of clinical scenarios or 
even incorporating activity tracking devices into curriculums to inspire health improvement among pharmacy students. Perhaps we can look to design professions and introduce an intentional focus on creative skills into the pharmacy curriculum, so that students can understand and practice their own creativity as it relates to the profession. I have been the most engaged in the courses where I am able to marry my creativity with my pharmacy knowledge.

Ideally, I would love to see a generation of pharmacy students comfortable with describing themselves as innovators, disruptors, and creators. It is clear that our role as pharmacists is changing rapidly, and to meet that evolution we need to change the language that pharmacy students use to describe their place in this shifting healthcare landscape. Our profession

\section{Conclusions}

Despite the debate surrounding the future of healthcare and the role of innovation in pharmacy education, one thing that is clear is that patients and students alike are demanding more from our system. A single concept like design thinking will not be the solution all of our questions, however the concepts of design thinking are powerful and enlighten us to the perspectives and ideas of others. As innovation demands new ways of thought and experimentation, we would be remiss to ignore the methods used to create many of the modern technologies we enjoy today to improve how we train the healthcare providers of tomorrow.

Acknowledgements: Thank you to Mark L. Tykocinski, MD, Rebecca Finley, PharmD, MA, FASHP and Brian Swift, PharmD, MBA for enabling and providing inspiration for this article.

Funding/Support: None

Other Disclosures: None

\section{References}

1. Cross N. Designerly Ways of Knowing: Design Discipline versus Design Science. Des Issues. 2001;17(3):49-55. doi:10.1162/074793601750357196

2. Gregory SA. Design Science. In: Gregory SA, ed. The Design Method. Butterworth, London: Springer US; 1966: 323-330.

3. Rittel, H.W.J. \& Webber, M.M. Dilemmas in a general theory of planning. Policy Sci. 1973;4(2):155-169. doi: 10.1007/BF01405730

4. Royalty A, Oishi LN, Roth B. Acting with Creative Confidence: Developing a Creative Agency Assessment Tool. In: Leifer L, Plattner H, Meinel C, ed. Design Thinking Research. Switzerland: Springer International; 2013: 79-96.

5. Rauth I, Köppen E, Jobst B, Meine C. Design Thinking: An Educational Model towards Creative Confidence. In: Toshiharu T, Nagai Y, ed. Design Creativity 2010. Kobe, Japan: Springer US; 2010. has already seen enormous growth within the last decade and it is continuing to expand as our graduates seek out opportunities that push the boundaries of the typical roles we expect pharmacists to hold. Now that there is a demand for our expertise in the technology and design spaces, we should recognize and seize the opportunity to change the face of our profession. Design thinking is the catalyst we need to revolutionize our ability to make meaningful change in these new roles. Going forward I'm hopeful that pharmacy students will recognize the value of design thinking in the evolution of our profession as we continue to traverse these new and challenging problems. It is also my hope, that they will acknowledge the importance of refining their creativity and look for radical ways to nurture it.
6. Patel RM. The Innovation Opportunity in Pharmacy Education Standards. Inov Pharm. 2017;8(3): Article 8.

7. Emerging Leaders 2018. Medicine $X$ at Stanford Medicine. https://medicinex.stanford.edu/emerging-leaders-2018. Accessed December 1st, 2017.

8. Medicine+Design. http://design-health.com. Accessed December 1st, 2017.

9. Industrial Design Students Help Develop Solutions for Paralyzed Teen. Jefferson Today.

http://wordpress.philau.edu/today/2016/12/16/industrialdesign-students-help-develop-solutions-for-paralyzed-teen Published December 16th, 2016. Accessed December 1st, 2017.

10. Accreditation Council for Pharmacy Education. Accreditation Standards and Key Elements for the Professional Program in Pharmacy Leading to the Doctor of Pharmacy Degree ("Standards 2016"). https://www.acpeaccredit.org/pdf/Standards2016FINAL.pd f. Published February 2015. Accessed Dec 1, 2017.

11. Medina MS, Plaza CM, Stowe CD, et al. Center for the Advancement of Pharmacy Education 2013 educational outcomes. Am J Pharm Educ. 2013;77(8): Article162. doi: 10.5688/ajpe778162

12. Michigan Tech Students to Turn Bowling Alley into "Makerspace" Lab. Crain's Detroit

Business.http://www.crainsdetroit.com/article/20151117/ NEWS01/151119855/michigan-tech-students-to-turnbowling-alley-into-makerspace-lab. Published November 17th, 2015. Last updated March 16th, 2017. Accessed December 1st, 2017.

13. ICE (Innovation, Creativity, and the Entrepreneurial Mindset), More Than Just a Cool Course. Union College website.

https://www.union.edu/news/stories/2017/04/iceinnovation,-creativity-and-the-entrepreneurial-mindsetmore-than-just-a-cool-course-.php. Published April 25th, 2017. Accessed December 1st, 2017. 